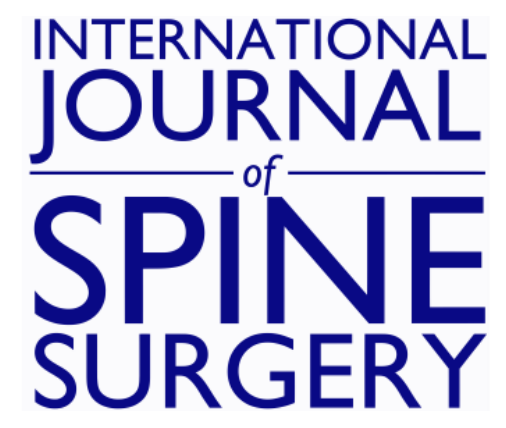

\title{
Intra-medullary Tuberculomas: Case Series
}

N. Pradeep, Raviraj Ghorpade, Ravishankar Naik and Prakash R Malur

Int J Spine Surg 2017, 11 (1)

doi: https://doi.org/10.14444/4002

http://ijssurgery.com/content/11/1/2

This information is current as of April 26, 2023.

Email Alerts Receive free email-alerts when new articles cite this article. Sign up at: http://ijssurgery.com/alerts

The International Journal of Sbinesurgerth 2397 Waterbury Circle, Suite 1,

Aurora, IL 60504, Phone: +1-630-375-1432

(C) 2017 ISASS. All Rights Reserved. 


\section{Intra-medullary Tuberculomas: Case Series}

Pradeep N., M.Ch, Raviraj Ghorpade M.Ch., Ravishankar Naik, DM, Prakash R Malur, MD

Department of Neurosurgery, Jawaharlal Nehru Medical College, Nehru Nagar, India

\section{Abstract}

Intramedullary spinal tuberculoma is an extremely rare disease when compared to pulmonary, extrapulmonary and skeletal tuberculosis in developing countries. In the absence of systemic tuberculosis, clinical presentation is non distinctive from other intramedullary lesions. We report two cases of intramedullary tuberculoma both presenting with signs and symptoms of space occupying lesions. Surgical excision was done in both cases following which patients improved neurologically. Histopathological evaluation is essential to provide curative treatment.

OTHER \& SPECIAL CATEGORIES

KEYWORDS: INTRAMEDULLARY, TUBERCULOMA, SPINAL

VOLUME 11 ISSUE 1 DOI: 10.14444/4002

PAGES 7 - 9

\section{Introduction}

Intramedullary tuberculoma is a rare cause of Spinal cord compression. Intradural spinal tuberculosis is rare while Intramedullary spinal tuberculomas (IMT) are still rare; ${ }^{1}$ the incidence quoted is two in 100,000 cases of all tuberculosis. ${ }^{2}$ Intramedullary spinal TB was first described by Abercrombie in 1828. ${ }^{3}$ Spinal intramedullary tuberculous abscesses (ITA) is still rare. ${ }^{4}$ We report two cases of intramedullary spinal tuberculoma.

\section{Case Report 1}

A 55-year-old man presented with asymmetric onset of paraparesis since five months. Initially he noticed weakness in the left foot since five months, followed by right foot since three months. Later, slowly progressing to proximal muscles. He noticed tingling and numbness in the left foot for 3 months which gradually ascended proximally. He had urinary urgency since two months. History of significant weight loss and loss of appetite since five months. No history suggestive of stiffness, involuntary movements, flexor spasm, thinning of muscles. Past history of tuberculosis, diabetes mellitus was absent.

On examination patient was conscious, oriented. Higher mental functions and cranial nerves appeared normal. On inspection of spine and cranium was normal. He had mild atrophy of left leg and foot muscles. He had asymmetrical paraparesis (right: proximal 4+/5, distal 4/5; left: proximal 4/5, distal 3/5).
Sensation below L3 level was impaired. Deep tendon reflexes normal in upper limb and sluggish in lower limb. Right side plantar response was extensor and left side was flexor. Cremasteric reflex was absent. Routine blood investigations was normal. Chest Xray was normal. MRI of spine plain and contrast revealed intramedullary peripherally hypointense lesion with central hyperintensity and perilesional edema at D12-L1 level on T2 W images with intense peripheral enhancement on gadolinium injection (Target sign) (Figure 1).

\section{Case Report 2}

A twenty-three-year-old woman presented with asymmetrical weakness of left upper and lower limbs since two months. She noticed tingling and numbness of left upper and lower limbs since three months. Initially she noticed weakness in the left hand and left foot which gradually ascended proximally. No history suggestive of limb stiffness, involuntary movements, flexor spasm, bowel and bladder disturbances. She was diagnosed with pulmonary tuberculosis with tubercular cervical lymphadenopathy and cold abscess two years back. She had completed her antitubercular treatment course following diag-

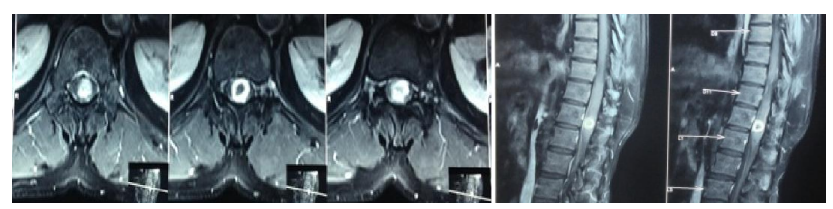

Fig. 1. Peripherally ring enhancing thick walled lesion with perilesional edema(target sign). 
nosis.

On examination patient was conscious and oriented. Higher mental functions and cranial nerves were normal. Inspection of cranium and spine was normal. She had asymmetrical weakness of upper limbs (right: proximal and distal 5/5; left: proximal 4/5, distal 3/5) lower limb (right: proximal and distal 5/5; left: proximal and distal 4/5). Upper limb and lower limb reflexes were exaggerated with left plantar extensor and right flexor. Sensation on left side below C5 level was decreased. Rest of the systemic examination was normal.

Routine blood investigation and chest x-ray was normal. Magnetic resonance imaging spine revealed intramedullary lesion at C4, 5 level which was hypointense on T2 $\mathrm{W}$ images and isointense on T1. Perilesional edema was present. On contrast, there was ring enhancement with central hypointensity (Figure 2).

Both patients were started on antitubercular and antiedema drugs. Both underwent laminectomy with midline durotomy and myelotomy with total excision of lesion. Post-operative recovery was uneventful. In both cases tuberculoma was confirmed on histopathology (Figure 3). Anti-tubercular treatment was continued. Post op follow up of case one with 18 months showed near normal lower limb power and normal sphincter functions. Case two follow up of six months showed good improvement in left extremities motor power with mild tingling numbness of left upper limb.

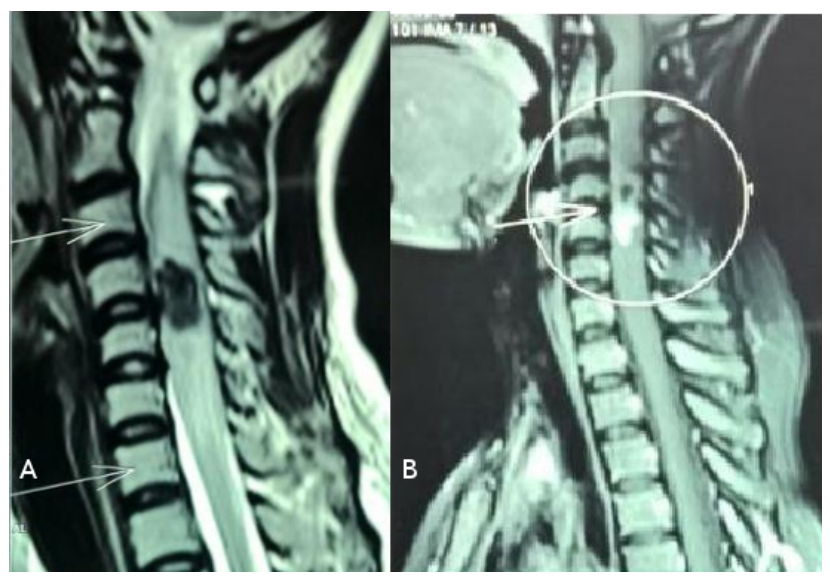

Fig. 2. (a) Hypointense with well-defined borders on $T_{2} W$, (b) images enhancing intensely on contrast injection with central hypointensity.

\section{Discussion}

Spinal intramedullary tuberculoma is a rare disease; its incidence among patients with tuberculosis is only two per 100,000 accounting for only two percent of all cases of central nervous system tuberculosis. The ratio of intramedullary tuberculoma to intracerebral tuberculoma is approximately $1: 42$ and $72 \%$ of lesions are located in the thoracic cord. ${ }^{4}$ Case one had dorsolumbar junction tuberculoma with no pulmonary disease. Spinal intramedullary tuberculoma is mostly induced by hematogenous dissemination or cerebrospinal fluid infection. Tuberculomas develop following haematogenous dissemination of bacilli from an infection elsewhere in the body, usually lung. Case two had pulmonary tuberculosis for which she had completed her antitubercular course and had cervical tuberculoma which is rare location. There is a slight male preponderance for intramedullary spinal cord tuberculoma (M:F, 1.5:1). Duration of symptoms at presentation varies from three to twenty months (mean 11.5 months). ${ }^{5}$

Chest radiographs and CT scanning are effective measures for the detection of pulmonary tuberculosis and extrapulmonary tuberculosis. For spinal intramedullary tuberculosis, MRI is the optimal measure because it can accurately show location, size, and number of lesions, as well as whether there is degeneration and necrosis around the lesions. In the early phase, the tuberculoma is characterized by severe infective reactions, poor formation of the gel capsule and severe edema around the lesion. During this phase, both $\mathrm{T}_{1 \mathrm{~W}}$ and $\mathrm{T}_{2 \mathrm{~W}}$ images show equal signal intensity and they are evenly enhanced after

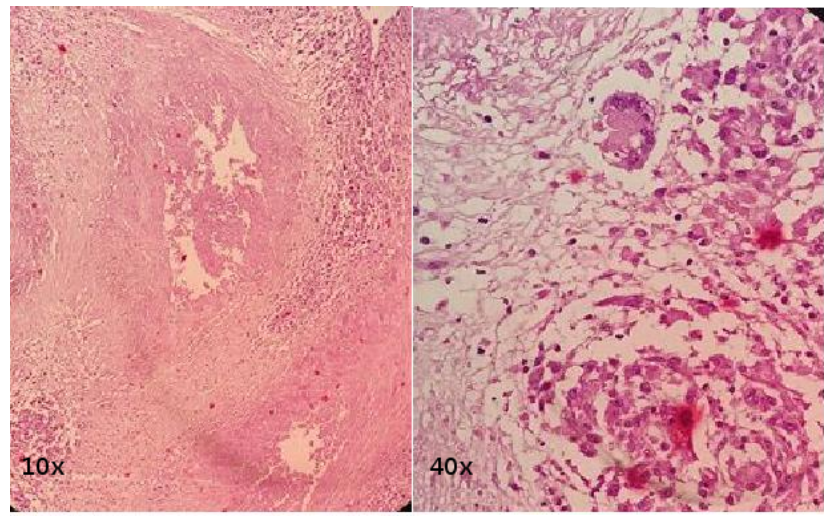

Fig. 3. HPR. 10x shows caseating granulomatous lesion and showing giant cell granuloma on $40 x$. 
being intensified. As the gel content in the tuberculoma increases, the peripheral edema is alleviated or may disappear. As a result, $\mathrm{T}_{1 \mathrm{~W}}$ images show equal signal intensity; meanwhile, $\mathrm{T}_{2 \mathrm{~W}}$ shows equal or low signal intensity. After enhanced scanning, there is rim enhancement and low signal in the central region. With the development of caseation, $\mathrm{T}_{2 \mathrm{~W}}$ images show a typical "target sign" ${ }^{6,7}$ which means that it exhibits a range from the low signal target to the high signal rim and also from the center of the low signal rim to the peripheral parts. Differential diagnoses include common spinal intramedullary tumors, such as astrocytic glioma, ependymoma, and hemangioblastoma. Preoperative antituberculous therapy for 1-2 weeks may avoid spreading of intraoperative tuberculosis. Careful dissection and resection could get good recovery for intramedullary tuberculoma with mass effect and paradoxical enlargement of the tuberculoma at late stage. ${ }^{8,9}$ Postoperative whole course antituberculous chemotherapy is mandatory.

\section{Conclusion}

Though spinal intramedullary tuberculomas are rare. It should be considered in the differential diagnosis of intramedullary lesions in developing countries. Timely intervention with surgery and chemotherapy yields good prognosis.

\section{References}

1. Rhoton EL, Ballinger WE, Quisling R, Sypert GW. Intramedullary spinal tuberculoma. Neurosurgery 1988;22:733-6.

2. Nussbaum ES, Rockswold GL, Bergman TA, Erickson DL, Seljeskog EL. Spinal tuberculosis: A diagnostic and management challenge. J Neurosurg 1995;83:243-7

3. Abercrombie J. Pathological and practical researches on diseases of brain and spinal cord. Edin- burgh: Waugh and Innes; 1828. p. 371-2.

4. Hanci M, Sarioglu AC, Uzan M, Işlak C, Kaynar MY, Oz B. Intramedullary tuberculous abscess; A case report. Spine 1996;15:766-9.

5. Sharma MC, Arora R, Deol PS, Mahapatra AK, Sinha AK, Sarkar C. Intramedullary tuberculoma of the spinal cord: a series of 10 cases. Clin Neurol Neurosurg 2002;104:279-84.

6. Chang KH, Han MH, Roh JK, Kim IO, Han MC, Choi KS, et al. Gd-DTPA enhanced MR imaging in intracranial tuberculosis. Neuroradiology 1990;32(1):19-25.

7. Gupta VK, Sharma BS, Khosla VK. Intramedullary tuberculoma: report of two cases with MRI findings. Surg Neurol 1995;44(3):241-3.

8. Nomura S, Akimura T, Kitahara T, Nogami K, Suzuki M. Surgery for expansion of spinal tuberculoma during antituberculous chemotherapy: A case report. Pediatr Neurosurg 2001;35:153-7.

9. Citow JS, Ammirati M. Intramedullary tuberculoma of the spinal cord: Case report. Neurosurgery 1994;35:327-30.

\section{Disclosures \& COI}

The authors report no relevant disclosures.

\section{Corresponding Author}

Dr. Pradeep N. MCh, Department of Neurosurgery, KLE'S Prabhakar Kore Hospital \& MRC, Jawaharlal Nehru Medical College, Karnataka, India. pradeeprachi12@gmail.com.

Published 10 January 2017.

This manuscript is generously published free of charge by ISASS, the International Society for the Advancement of Spine Surgery. Copyright $\odot 2017$ ISASS. To see more or order reprints or permissions, see http://ijssurgery.com. 